\title{
Fouling and its next generation management: a perspective
}

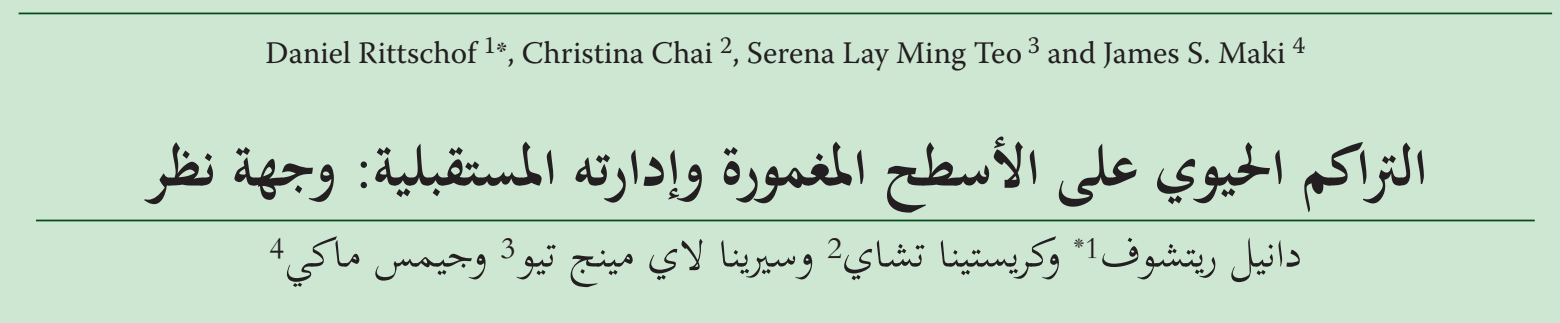

ABSTRACT. The last 50 years of fouling research and management taught us that indiscriminate use of toxic approaches damages ecosystem services of estuaries and oceans critical to man's existence. Next generation environmentally benign management requires knowledge of the fouling process and an understanding of the consequences of different management options. An intermediate step may be additives that fit with existing business models and distribution systems, but that carry a much reduced environmental footprint. Subsequently, the evolution of a next generation hull fouling management system with limited toxicity easy clean surfaces should replace or augment the existing commercial easy-release coatings. These new technologies require new business models and infrastructure. The path for a new commercial hull coating, from a concept to the actual product takes 25 to 35 years to complete. Major challenges include fitting in with existing business models and systems and meeting regulations. Leveraging on our experience in the development of additives as a case example, we offer a perspective on what the new fouling management systems might involve and discuss issues to be addressed as limited toxicity easy-clean coatings gain market share. As existing business cannot easily adapt to a different business model, evolution of new management solutions will require resources, a necessary long term perspective, and close working relationships between business and science to enable products in the global market.

Keywords: fouling management, foul release, low toxicity antifouling, ship coatings, aquaculture net coatings

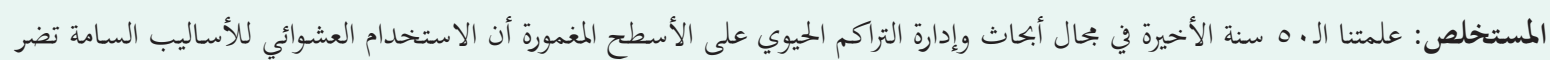

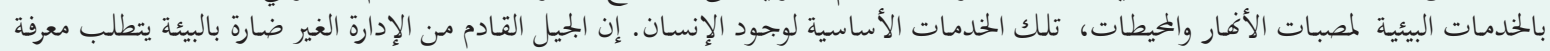

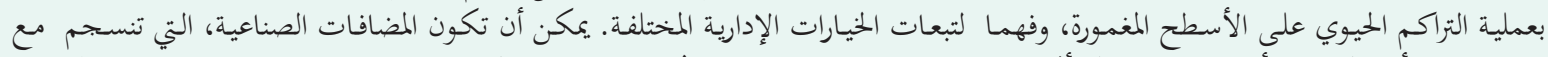

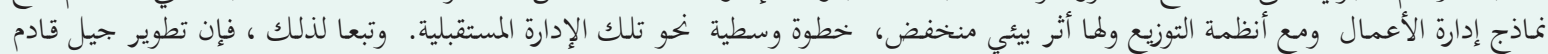

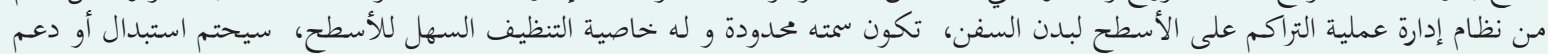

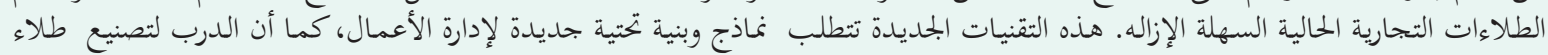

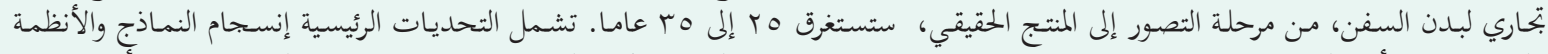

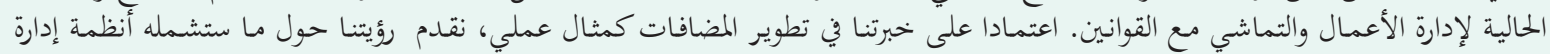

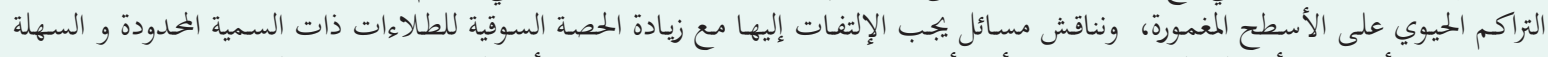

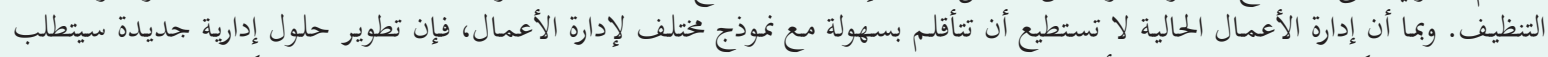

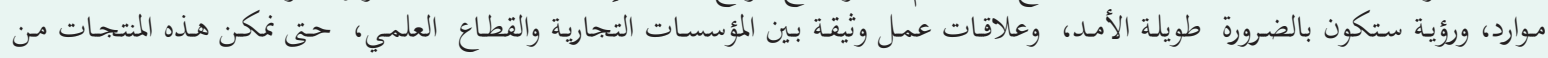
التواجد في السوق العالمية.

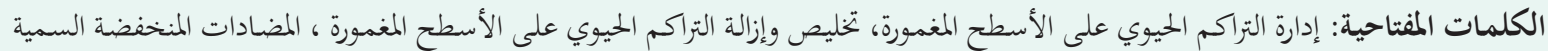

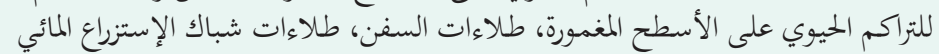

\section{Introduction}

$\mathrm{B}$ iofouling is the accumulation of biological materials onto surfaces submerged in water. Biofouling occurs at molecular, microbial and macro-organism levels and the different levels may either interact or

*1 Daniel Rittschof $(\square)$ Duke University Marine Laboratory, Beaufort NC 28516 USA. email: ritt@duke.edu.

2 Department of Pharmacy, National University of Singapore, 18 Science Drive 4, Singapore 117543.

3 Tropical Marine Science Institute, National University of Singapore,

18 Kent Ridge Road, Singapore 119227.

${ }^{4}$ Department of Biological Sciences, Marquette University, P.O. Box 1881, Milwaukee, Wisconsin 53201-1881 USA. occur independently of other levels. Fouling of surfaces in marine environments is most complex and exemplifies a dynamic range of potential interactions (Figure 1, Clare et al., 1992).

Molecular fouling is often referred to as the conditioning film. Every surface submerged in the ocean interacts with biological molecules and rapidly - within seconds - a conditioning film forms. Conditioning films occur at the air/water interface, at the interface of currents and internal waves and whereever there is a physical boundary. Films form virtually instantaneously. An example is the phenomenon called sublation in which air bubbles strip surface active organic molecules from water. Conditioning films take on stable physical chemical characteristics after about 3 days. 
Fouling by microbial organism is called microfouling. Microfouling is broadly defined to include the diverse community of organisms, including bacteria, diatoms, fungus, cyanobacteria and other microbes which science is just beginning to discover (Maki and Mitchell, 2002; Qian et al., 2007; Dobretsov, 2010). Microfouling attachment events are often relatively rapid, on the order of hours for firm attachment. Attachment is based on the same kinds of chemistry as molecular fouling. However, the development and evolution of the microbial biofilm is a much slower process and may take hours to days.

Macrofouling is the term normally applied to multicellular mobile as well as sessile organisms visible to the naked eye (Woods Hole Ocenaographic Institution, 1952; Turner, 1984; Crisp, 1984; Haderlie, 1984; Clare et al., 1992). In practice, research focus has been mainly on the sessile organisms. The initial events in sessile macrofouler attachment occur in minutes, use specialized glues, and attachment is roughly as fast or faster than for microbial fouling.

The extremes of the possible fouling scenarios are depicted in Figure 1a and b. At one end of the spectrum is the classical sequential scheme that occurs in systems that have co-evolved. In this scenario molecular fouling occurs first followed by microfouling which is followed by algal and invertebrate larval fouling. In fouling communities the best example of this scenario is settlement of calcareous tube building worms like Hydroides elegans (Hadfield 2011, and references therein). In biofouling systems managed on man-made structures and especially in polluted and eutrophic harbors, this scenario is rare because the marofoulers are "weed species" that that are found in these harbors globally. Many "weed species" were brought to harbours by ships so long ago that the origins of some globally common foulers are unknown.
The other end of the macrofouling spectrum is depicted in the scenario of Figure 1b. In this scenario there are two kinds of sinks, 1) surfaces and 2) aggregation of surface active molecules, polymers and propagules. Marine snow (Alldredge and Silver 1988, Alldredge and Gotschalk 1990, Passow et al., 2001) is an aggregate of bacteria, polymers and propagules that aggregate in the water column and precipitate as long strands. These strands stick to submerged surfaces as do individual micro- and macrofoulers. In this scenario what settles on the surface is what is most abundant and arrives on the surface first. As small molecules are vastly more common than micro- or macrofoulers, they would colonize a new surface first. Subsequent events follow no particular order, and the space is filled largely on a first come first serve basis. This is the dominant scenario for most fouling communities in harbors around the world.

Once colonization of a newly submerged surface begins, the interactions can become bewilderingly complex. Certain fouling organisms may inhibit the colonization by others (Rittschof et al., 1992b). Predation and sloughing create space for growth (Sutherland and Karlson 1977). Longer lived superior competitive species eventually dominate unprotected surfaces. In most instances, the dominance occurs at least seasonally and often on the order of several years to decades (Sutherland, 1977). Surfaces coated with toxic substances, such as ablative fouling management systems generally support smaller amounts of fouling. Well-functioning systems have a continuous film of microfouling and macrofouling cover from 5 to $20 \%$.

Setting aside the morass of biological detail, the basic "take-home" messages are (Rittschof, 2000):

1. All man-made surfaces submerged in water will foul.

2. Fouling has enormous economic impacts contrib-
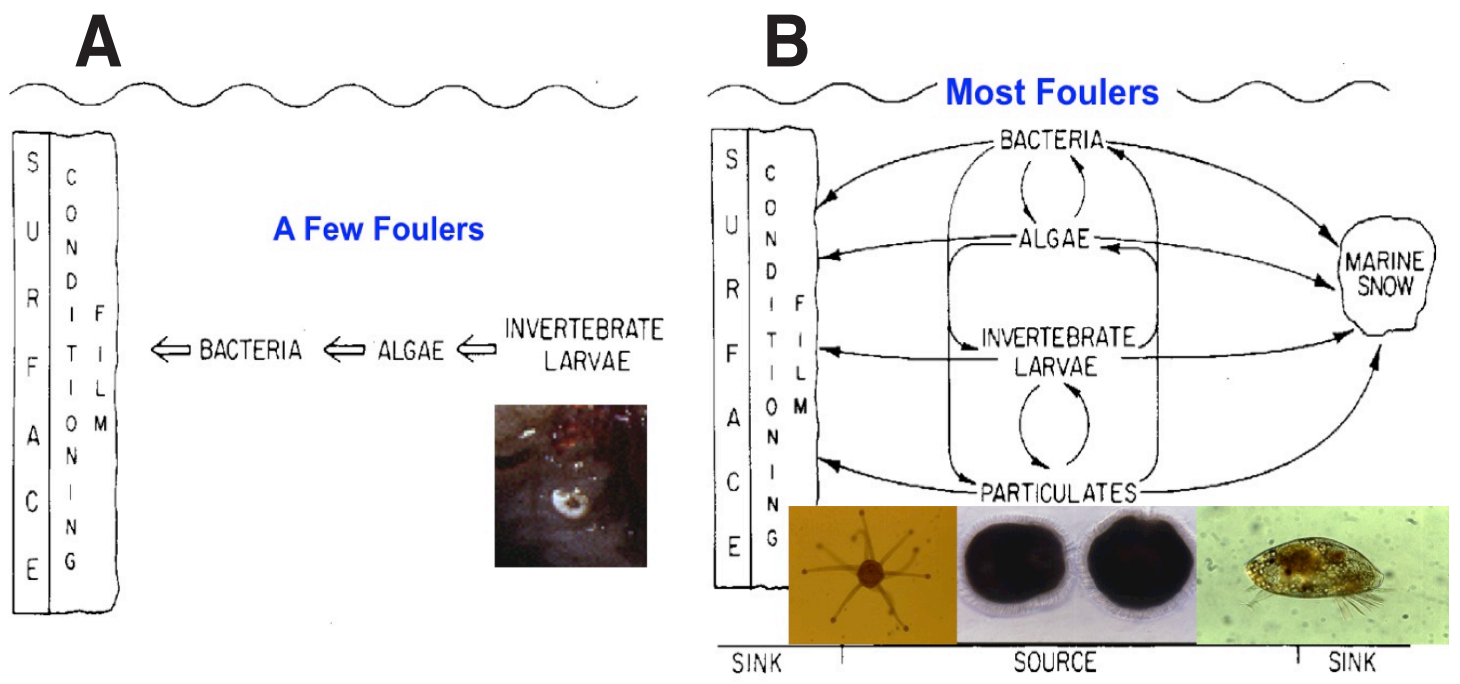

Figure 1. (A) Successional fouling vs (B) Stochastic fouling. 
uting to an overall increase in operational costs.

3. Fouling is biologically diverse and has passive and active living components. Thus, multifunctional solutions including some form of toxin may be necessary for management of fouling.

4. Fouling management needs to be minimally toxic because toxins are indiscriminate in their impact on ecosystem services essential to global health.

\section{Commercial fouling management coatings}

Management of surface fouling preceded environmental awareness by several thousand years (Woods Hole, 1956). As human populations increased and environments degraded, one consequence was terribly toxic fouling management solutions were discontinued in favor of coatings containing less environmentally damaging toxins. In recent history, the environmental impacts of some of the toxic additives (lead and organotins, for example) were replaced with toxins like copper and zinc. This "mix and kill" business model focuses on stable toxins like copper oxide that can be mixed easily into the paint are effective and have chemistry that is compatible with curing of the polymer film.

Business models for fouling management systems may be broadly grouped by looking at fouling management products. The first group of products focuses on release of biological active chemicals and consists of antifouling coatings of two major types: 1) resin/rosin coatings and 2) ablative copolymer coatings. The resin/ rosin coatings are thick spongy coatings that release toxic compounds, historically copper ions at a controlled rate. The ablative copolymer coatings are harder coatings that self polish by hydrolysis of the matrix and release toxic compounds as they polish. Historically these coatings all released copper ions (Wods Hole Oceanographic Insitituiton, 1952, Preiser et al., 1984). As environmental regulations restrict the amount of copper that can be released into the environment, the solution that is consistent with the presumed business models is

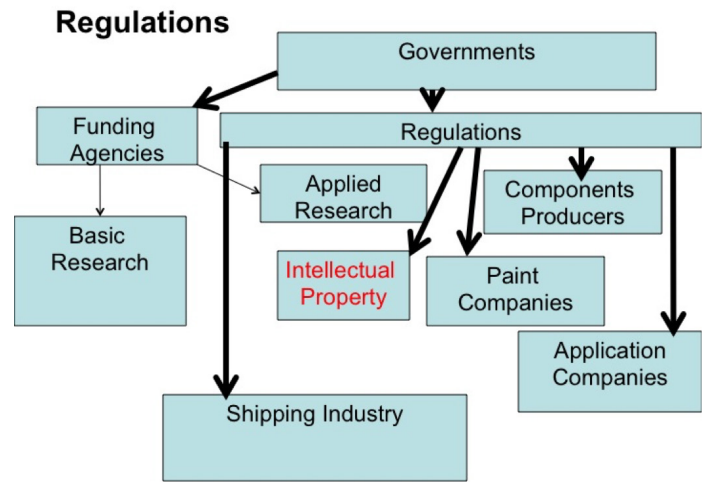

Figure 2. Government regulations. to reduce copper release but retain efficacy of the coating by releasing a different broad spectrum toxin, usually one or more long lived organic biocides.

The biocides of commercial choice are broad spectrum stable biocides that have chemistry compatible with curing of the polymer film. Most of these biocides are stable, long lived organic biocides (half lives on the order of a year or more) that do not interfere with the cure of the antifouling film. (Rittschof pers. observation) Sometimes the literature refers to these long lived organic biocides as "booster biocides". Since these biocides are just as toxic or more toxic than copper ions, they are better considered as co-biocides.

The toxic biocide fouling management business models originated over 50 years ago. Over time due to massive increases in commercial shipping, the mix and kill model has become increasingly unsustainable because it is environmentally unsound (Rittschof 2009 and references therein). As a result of environmental degeredation, governments are generating more strict regulations on toxin levels which force the businesses to find and incorporate new kinds of toxins to mix into paints. Then, as the new additives gain market share the new toxins build up in the environment, environmental impacts become apparent, new regulations are imposed and the cycle repeats itself. It is clear to those in the industry that mix and kill will be replaced with a different strategy.

Another consequence of the mix and kill model is it impacts development of new products. In development, the performance of new fouling management is compared to a standard of an existing coating with desired fouling management performance, but with unacceptable environmental impacts. New approaches are eliminated if they do not perform as well as the environmentally unacceptable alternatives. Thus, new business models and evaluations are needed before major changes in the industry can take place (Rittschof, 2000).

For most economies, governmental regulations (Fig. 2) have a major impact on every aspect of the business of generating, shipping, applying and removal of antifouling coatings. On the other hand, basic and

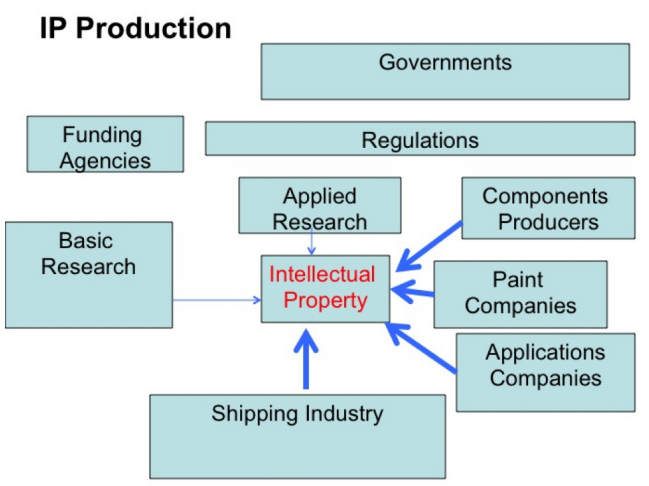

Figure 3. Intellectual property. 
Top-down approach

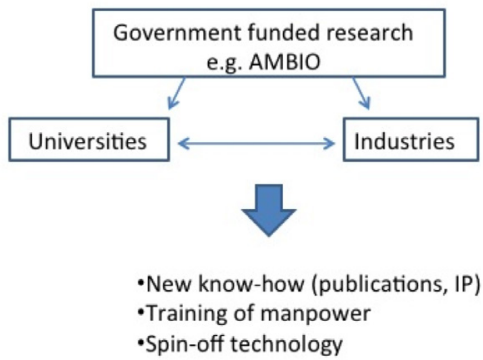

Figure 4. Multidisciplinary Targeted Government Programs.

applied research on fouling coatings development is the least regulated of these components. One of the most difficult and expensive transitions is the regulatory path that moves intellectual property, e.g., the development of new fouling management additives, to commercial availability. There are significant temporal and financial barriers to additive development (Rittschof, 2000; 2009). In the late 1990s satisfying the regulatory process for the short lived additive, the isothiazalone Sea Nine 211 was reported to take over 10 years and cost approximately US $\$ 11,000,000$.

Another fascinating aspect of coatings development is the development of Intellectual Property (IP). Although an academic might think that government funded research is the source of intellectual property, the reality is that most of what becomes commercially valuable intellectual property is developed in-house by companies at various nodes of the product production and application chain (Fig. 3). IP can be patented or become a trade secret. Often companies keep their IP as trade secrets because patenting provides competitors with know-how and the information that facilitates the discovery of similar unprotected alternatives. The academic business model of protecting IP by patenting does not provide the advantage that trade secrets provide during research and development.

For development of novel fouling management alternatives there are "top-down" and "bottom-up" projects. Japan uses "top-down" projects to train researchers who then move into the private sector (i.e., the Fusetani Biofouling Project). The European Union AMBIO Project (Figure 4.) is an example of a "top-down" project that features government funded collaboration between academia and industry. This preplanned and phased project is transitioning to Phase II. Since we are not involved directly in this project, we do not know the details of the relationships between the members of this group.

The "bottom up" approach to development of novel additives and coatings is usually initiated by individual or small groups of academic researchers (Fig. 5). When initiated, the "bottom-up" approach is focused on a more

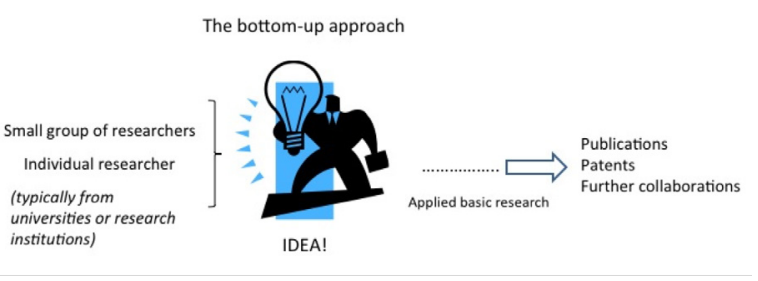

Figure 5. Academic style inspired research.

narrow research thread and concepts. The research program usually starts as a whitepaper or workshop. The work is not extensively preplanned but evolves as the research concept develops. With a "bottom up" process one starts with a small team that grows and changes as the program matures.

The bottom-up approach is less structured and requires less initial outlay of funds. The research and team are organic in the sense that participants are recruited to the program as the research need is identified. This approach is attractive to academics because they are in control of the directions the research takes and can address issues like toxin half life from the beginning. It starts with hypothesis testing of a conceptual frame work with application as a long term goal.

As an example, we document herewith an academic journey detailing our research efforts to generate an environmentally benign anti-fouling additive suitable for marine coatings. At this time of writing, we are 13 years into a journey that -based on the Sea Nine 211 experience - may take 25 to 35 years for successful completion.

In 1999, a white paper was raised presenting the case that pharmaceuticals provide a good source of potential antifoulant additives. The rationale was that one could interrupt the transduction cascade that initiates metamorphosis of macrofouling larvae to prevent settlement and adhesion (Rittschof et al., 2003). The general logic stream was: evolution is real; invertebrates and vertebrates share biochemical and signaling pathways; pharmaceuticals that impact signaling pathways in vertebrates have potential for interrupting pathways that initiate metamorphosis of macrofouling organisms; pharmaceuticals have known chemical synthesis and properties as well as biochemical mechanisms of action and degradation pathways. The plan was to begin the research by choosing molecules that could be adapted to the mix and kill business model but that would interrupt macrofouling metamorphosis transduction cascades, but with the caveat that all components would have biological half lives of less than a month.

Our white paper acknowledged that some form of short lived toxin would be necessary to enable effective 

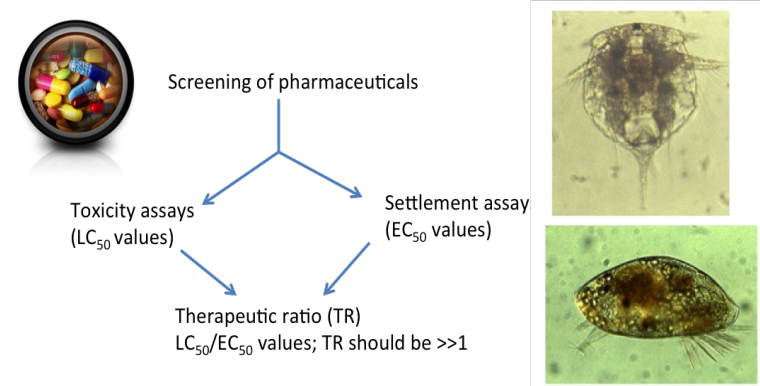

Figure 6. Overview of testing methods .

delivery of other active ingredients across the biofilm. We postulated that there were pharmaceuticals that are low toxicity and high potency, thereby enabling them to fit into a business model modified from mix and kill, to mix and inhibit. In reality many of the animals on a hull would actually be killed. However, the advantage was we could minimize the impact on non-target species by employing biodegradable short lived compounds. Up front the plan included the concept of therapeutic ratio (TR) the concentration required for toxicity vs. the concentration required for efficacy as well as biodegradation studies (Rittschof et al., 1992). The TR is the ratio is the number generated by dividing the concentration required to kill fifty percent of the larvae by the concentration required to inhibit $50 \%$ of the larvae from settling. A TR of 1 is a toxic mechanism. A TR of 25,000 is a molecule that prevents settlement but does not kill larvae and was the kind of result we were looking for. Our original upper cut-off for consideration was an EC50 < $25 \mathrm{ug} / \mathrm{ml}$. The cut-off was chosen based upon calculations of levels of compounds that could be loaded into a coating that would result in a coating with a commercially viable lifetime.

When sent to US funding agencies the white paper was not taken up. However, Asia was booming economically and the maritime industry was moving their business to meet the demand from a huge expansion of ports in China. For the research we had in mind, we looked to Singapore for necessary attributes: high investment in education and $R \& D$, legal frameworks for technology protection, and physical presence of a vibrant pharmaceutical/chemicals and shipping industry. We, Dan Rittschof, Duke University, James S. Maki from Marquette University and Serena Teo at the Tropical Marine Science Institute of the National University of Singapore developed a white paper. Dr. Teo organized a workshop in Singapore around that whitepaper and this resulted in several agencies expressing interest. Subsequently, the Agency for Science, Technology and Research (A*STAR) in Singapore funded the initial work.

The TMSI team began as a team of planners/researchers (Teo, Maki and Rittschof) two post-doctoral fellows and two technicians. The program began with biofouling bioassays and pharmaceuticals. The laboratory and field bioassays were fast, highly quantitative and designed for microgram amounts of material.

We started with a sense of humor. Everyone brought in samples of the pharmaceuticals they had in their refrigerators. We could do the research and generate the data we needed with less than 500 micrograms $(<<$ than one pill) of any pharmaceutical. We subjected each pharmaceutical to microbial and barnacle bioassays.

In short order we categorized the drugs by their vertebrate mode of action, effectiveness, toxicity, water solubility and therapeutic ratio. In retrospect, this was a good idea because as time passes and techniques of metabalomics and proteomics become more sensitive, an abundance of systems that were first described in vertebrates are represented in invertebrates. Many common pharmaceuticals are extremely potent at interrupting larval barnacle settlement. We tested 20 compounds with 8 known primary mechanisms of action in vertebrates. We found compounds effective at nanogram per $\mathrm{ml}$ concentrations and with therapeutic ratios from less than one (highly toxic) to over 1250 minimally toxic, but effective (Rittschof et al., 2003). An EC50 < $40 \mathrm{ng} / \mathrm{ml}$ with an LC50 > $25 \mathrm{ug} / \mathrm{ml}$ was an exciting experimental result.

Our team generated similar data for over 20 strains of marine bacteria (Chong et al., 2010). We found compounds that were bactericidal, bacteriostatic and that inhibited bacterial adhesion. Multiple functions of biologically active molecules are the rule rather than the exception.

From these initial studies, we chose to focus on a pharmaceutical which is and Opiod E2 receptor agonist in vertebrates. Most travelers know the pharmaceutical as Imodium ${ }^{\ominus}$. A glance at the structure and knowledge of how the drug works in humans is sufficient to begin the conversation about our next set of challenges (Fig. 7).

Anyone who has taken Imodium ${ }^{\bullet}$ is aware of two things 1) the drug works quickly; 2) the drug works for a relatively long time. These features are great. They support the observation that the drug is highly potent and stable. Although stability is great for a mix and kill business plan, this drug is too stable for large scale use in the environment, especially if the commercial product gained market share. The result could be disastrous for the environment and would definitely cause huge discomfort to many environmental scientists, as has been demonstrated by compounds such as Irgarol which is a photosystem II inhibitor, and other organic toxins with half lives longer than 3 months. Our research led to new targets: how to simplify and de-engineer molecule so it would still be effective, but it would break down.

A new partnership was thus formed: with synthetic chemists in the A*STAR institute, Institute of Chemical Engineering Sciences (ICES) interested drug design. 


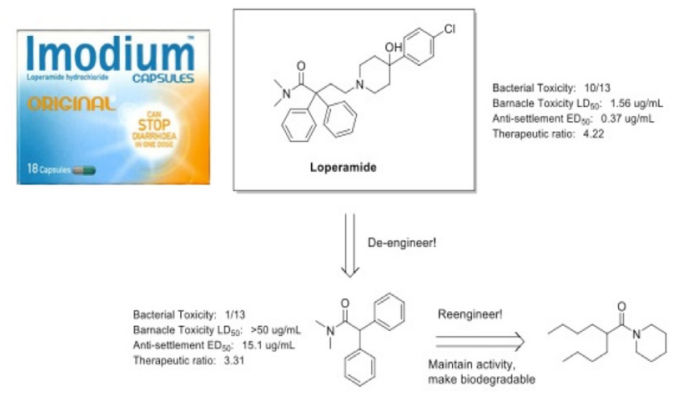

(1)

(2)

Figure 7. Deengineering to an active pharmacophore.

This group included synthetic and polymer chemistry expertise. The challenge was in bridging the gap between chemistry and biology. We took advantage of knowledge gained in a QSAR study conducted by Pettis et al., (1989) with biologically active peptides. In that study it was discovered that simple alkyl chains could be used to replace rings. This is important because rings have many other biological activities and break down slowly.

From the earlier drug screening we identified Imodium $^{\ominus}$ (Fig. 7-1) as the most promising starting point. However, the molecule is remarkably large, endowed with complex resonance and likely to generate a bewildering array of biologically active components (pharmacophores) as it breaks down. We decided to look for a smaller less stable pharmacophore with the biological activity we wanted. We divided the molecule approximately in half and found that both halves were biologically active. When we looked at the halves, we made the decision to see if the left hand side of the molecule on figure 7 (1) could be modified because it resembled part of a peptide. Based on previous QSAR experience with the peptide receptor (Pettis et al., 1989) and with our talented synthetic chemists a series of molecules that substituted 4 carbon chains for the two refractory rings. We incorporated the one amide nitrogen we kept into a ring and found that was an excellent pharmacophore. We called the molecule on figure 7 (2) the "two legged man". It had substantial biological activity, was easy to synthesize and it became the center of another patent disclosure.

These new discoveries enabled us to gain more funding and continue to grow our team. We increased the involvement of polymer chemists, as the new challenge was in finding ways to deliver our biologically active molecules from conventional antifouling coatings such as the zinc acrylate self polishing coating (Fig. 8). Looking ahead to future easy release coatings we also began to work with a polydimethyl siloxane film. We began the process of finding ways to deliver pharmacophores in a curable matrix. The simplest way forward was to generate a low solubility powder that could be mixed into the coating. Another attractive option was to attach pharmacophores to particles which could be mixed into coatings (Fig. 9). Part of this approach was adding a handle onto the molecules to enable attachment or to enable generation of a block for a polymer or copolymer. Bioassays guided the chemistry as we needed modifications that did not destroy the desired biological activity.

Scientific progress is double edged sword. Whereas academic pursuits favor the dissemination of information, business models inevitably involve intellectual property (IP) issues. In order for successful commercialization, IP must be protected in order for a company to be interested. Given the organic nature of the bottom up research, IP ownership issues were not clearly defined at the onset as partnerships changed and the research evolved. A consequence is a variable number of (fund-

\section{Research Planners}

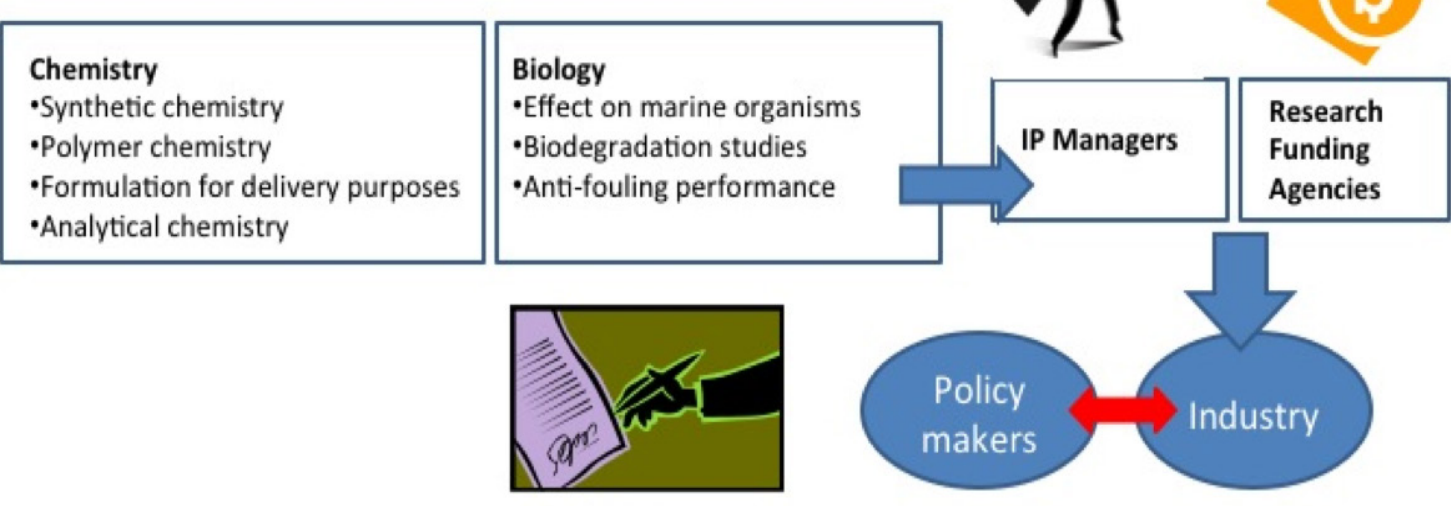

Figure 8. The next program phase 


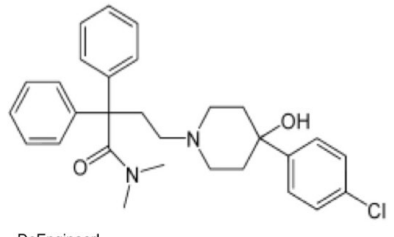

DeEngineer:

Maintain Activity Make Biodegradable

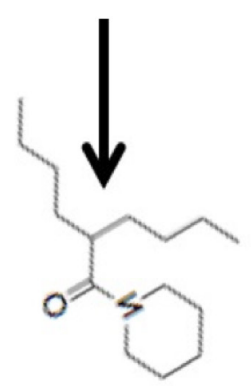

Reengineer!

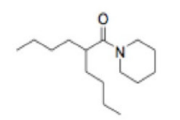

Maintain Biodegradability

Dry Powder for Mixing in Acrylate Coatings

Enable Coupling to Polymers or Surfaces for Slow Release

Oil for delivery in Foul Release Coatings

Generate Homo and DiBlock Polymers

Figure 9. Creating environmentally benign biologically active small molecules.

ing) agencies had rights to the technology, resulting in patent ownership which was complex. Most agencies do not have an understanding of a development process that often spanns 10 to 15 years to commercialization. Deliverables were considered only within the confines of the specific project on hand. As such, research progress was stalled and research teams compromised, while intellectual property issues were negotiated.

It would appear then that the first challenge, which seems a deviation from the path to productivity, is to sort out the IP. As researchers are interested in going forward with development and had immediate goals of a fun job, they routinely decline or sell their right to the property. This suggests that the progress of technology development may lie out of the hands of researchers and in the hands of IP professionals, lawyers and administrators. But, unhappily for project progress, none of these groups are familiar with product development. As a consequence, there remain conflicting perspectives. In addition to the formidable challenge of IP, commercialization of environment technologies must meet necessary regulatory requirements that demand once again, scientific data (Rittschof, 2000). Given the potential va-

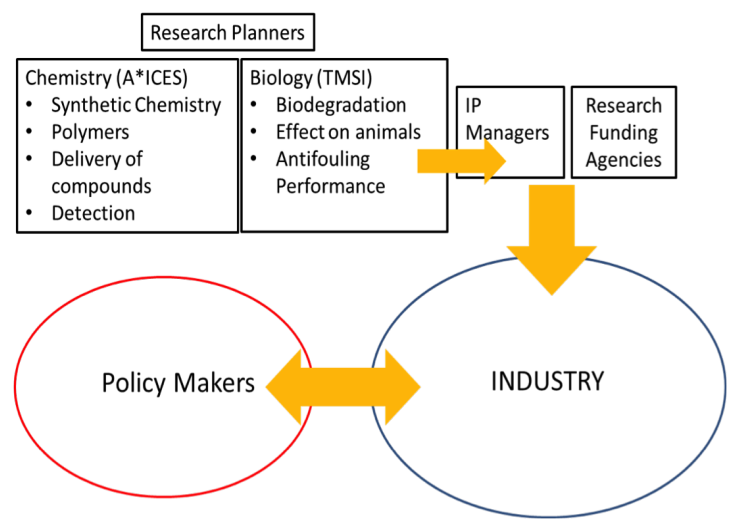

Figure 10. The existing pathway for $R \& D$ places the initial research at a distance from environment policy. Such a model is not optimal for the development of environment benign technologies as a first selective step ranks technologies by efficacy alone, thereby eliminating benefits from optimization of candidates that can meet regulatory requirements. An improved holistic development model would include multiple interactions between different stakeholders to facilitate faster evolution of the technology.

riety of inter-related technology that may arise out of any given patent, these data requirements will vary from sector to sector, and between regions. Thus, it appears that sustainable environment research today demands a new integrated research-business model that embraces multiple cross-disciplinary conversations and elements throughout the product life cycle (Fig. 10). Such a model is necessary to expedite technology development as risks for investors increase exponentially over time.

On both fronts we have hope. The world is changing very quickly with respect to globalization and fouling management goals. This is especially true due to continued growth of human populations. There is increasing understanding of the importance of marine products in feeding the world. With the global crash of natural harvest fisheries aquaculture is increasingly important. Combined with climate change and sea level rise societal understanding that biologically viable coastal oceans are central to the future of the planet has improved. One tenet of that understanding is toxic inputs must be reduced. These societal pressures will accelerate change and provide opportunities to develop alternative approaches. Figure 8 depicts the next phase of our program. We believe our children will benefit from our efforts.

\section{References}

Alldredge, A.L., and M.W. Silver. 1988. Characteristics, dynamics and significance of marine snow. Progress in Oceanography 20: 41-82

Alldredge, A.L., and C.C. Gotschalk. 1990. The relative 
contribution of marine snow of different origins to biological processes in coastal waters. Continental Shelf Research 10: 41-58.

Choong, A.M.F., J.S. Maki, J.T.B. Ikhwan, C-L Chen, D. Rittschof, and SL-M Teo. 2010. Pharmaceuticals as antifoulants: Inhibition of growth and effects on adhesion of marine bacteria. pp 221-246. In, J Chan \& S Wong,eds, Biofouling: Types, Impact and Anti-Fouling, Nova Science Publishers, Inc.

Clare, A.S., D. Rittschof, D.J. Gerhart, and J.S. Maki. 1992. Molecular approaches to nontoxic antifouling. Invertebrate Reproduction and Development 22: $67-$ 76.

Crisp, D.J., 1984. Overview of research on marine invertebrate larvae. 1940-1980. In: Marine biodeterioration an interdisciplinary study. Eds. J.D. Costlow and R.C. Tipper. Naval Institute Press pp 103-125.

Dobretsov, S. 2010. Marine biofilms. . In: S. Dürr and J.C. Thomason, eds., Biofouling. Wiley-Blackwell, Oxford. pp 123-136.

Hadfield, M.G. 2011. Biofilms and marine invertebrate larvae: what bacteria produce that larvae use to choose settlement sites. Annual Review of Marine Science 3: 453-470.

Haderlie, E.C. 1984. A brief overview of the effects of macrofouling. In: Marine biodeterioration an interdisciplinary study. Eds. J.D. Costlow and R.C. Tipper. Naval Institute Press pp 163-166.

Maki, J.S., and R. Mitchell. 2002. Biofouling in the marine environment. pp 610-619. In: G. Bitton, ed., Encyclopedia of Environmental Microbiology. John Wiley \& Sons, New York.

Passow, U., R.F. Shipe, A. Murray, D.K. Pak, M.A. Brzezinski, and A.L. Alldredge. 2001. The origin of transparent exopolymer particles (TEP) and their role in the sedimentation of particulate matter. Continental Shelf Research 21: 327-346.

Pettis, R.J., B.W. Erickson, R.B. Forward jr, and D. Rittschof. 1993. Superpotent synthetic tripeptide mimics of the mud crab pumping pheromone. Int. J. Prot. and Peptide Research 42: 312-319.

Preiser, H.S., A. Ticker, G.S. Bohlander, and D. W. Tayor. 1984. Coating selection for optimum ship performance. In: Marine biodeterioration an interdis- ciplinary study. Eds. J.D. Costlow and R.C. Tipper. Naval Institute Press pp 223-229.

Qian, P.-Y., S.C.K. Lau, H.-U. Dahms, S. Dobretsov, and T. Harder. 2007. Marine biofilms as mediators of colonization by marine macroorganisms: implications for antifouling and aquaculture. Marine Biotechnology 9: 399-410.

Rittschof, D. 2000. Natural product antifoulants: one perspective on the challenges related to coatings development. Biofouling 15: 119-127.

Rittschof, D. 2009. Novel Antifouling Coatings: A multiconceptual Approach, pp 179-188, in, Flemming $\mathrm{H}-\mathrm{C}$, PS Murthy, R Venkatesan, KE Cooksey (eds) in, Marine and Industrial Biofouling. Springer Publishing, NY.

Rittschof, D., A.S. Clare, D.J. Gerhart, Sr Avelin Mary, and J. Bonaventura. 1992. Barnacle in vitro assays for biologically active substances: Toxicity and settlement inhibition assays using mass cultured Balanus amphitrite amphitrite Darwin. Biofouling 6: 115-122.

Rittschof, D., C.H. Lai, L.M. Kok, and SL-M Teo. 2003. Pharmaceuticals as antifoulants: concept and principles. Biofouling 19(Suppl): 207-212.

Turner, R. D. An overview of research on marine borers: past progress and future directions. In: Marine biodeterioration an interdisciplinary study. Eds. J.D. Costlow and R.C. Tipper. Naval Institute Press pp 3-16.

Sutherland, J.P., and R.H. Karlson. 1977. Development and stability of the fouling community at Beaufort, North Carolina. Ecological Monographs 47: 425-446.

Woods Hole Oceangrpic Institution. 1952. Marine fouling and its prevention. Annapolis, U.S. Naval Institute. 